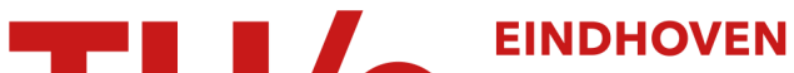 UNIVERSITY OF TECHNOLOGY
}

\section{Zeta potentials of tristearoylglycerol crystals in olive oil}

Citation for published version (APA):

Arts, T. J. C., Laven, J., Voorst Vader, van, F., \& Kwaaitaal, T. (1994). Zeta potentials of tristearoylglycerol crystals in olive oil. Colloids and Surfaces A: Physicochemical and Engineering Aspects, 85(2-3), 149-158. https://doi.org/10.1016/0927-7757\%2893\%2902712-N, https://doi.org/10.1016/0927-7757(93)02712-N

DOI:

10.1016/0927-7757\%2893\%2902712-N

$10.1016 / 0927-7757(93) 02712-\mathrm{N}$

Document status and date:

Published: 01/01/1994

\section{Document Version:}

Publisher's PDF, also known as Version of Record (includes final page, issue and volume numbers)

\section{Please check the document version of this publication:}

- A submitted manuscript is the version of the article upon submission and before peer-review. There can be important differences between the submitted version and the official published version of record. People interested in the research are advised to contact the author for the final version of the publication, or visit the $\mathrm{DOI}$ to the publisher's website.

- The final author version and the galley proof are versions of the publication after peer review.

- The final published version features the final layout of the paper including the volume, issue and page numbers.

Link to publication

\section{General rights}

Copyright and moral rights for the publications made accessible in the public portal are retained by the authors and/or other copyright owners and it is a condition of accessing publications that users recognise and abide by the legal requirements associated with these rights.

- Users may download and print one copy of any publication from the public portal for the purpose of private study or research.

- You may not further distribute the material or use it for any profit-making activity or commercial gain

- You may freely distribute the URL identifying the publication in the public portal.

If the publication is distributed under the terms of Article $25 f a$ of the Dutch Copyright Act, indicated by the "Taverne" license above, please follow below link for the End User Agreement:

www.tue.nl/taverne

Take down policy

If you believe that this document breaches copyright please contact us at:

openaccess@tue.nl

providing details and we will investigate your claim. 


\title{
Zeta potentials of tristearoylglycerol crystals in olive oil
}

\author{
T.J.C. Arts ${ }^{\mathbf{a}, 1}$, J. Laven ${ }^{\mathrm{a}, *}$, F. van Voorst Vader ${ }^{\mathbf{b}}$, Th. Kwaaitaal ${ }^{\mathbf{c}}$ \\ ${ }^{a}$ Department of Chemical Engineering and Chemistry, Eindhoven University of Technology, P.O. Box 513, \\ $5600 \mathrm{MB}$ Eindhoven, The Netherlands \\ ${ }^{\mathrm{h}}$ Unilever Research Laboratorium, Olivier van Noortlaan 120, 3133 AT Vlaardingen. The Netherlands \\ ${ }^{\mathrm{c} D e p a r t m e n t}$ of Electrical Engineering, Eindhoven University of Technology, P.O. Box 513, 5600 MB \\ Eindhoven, The Netherlands
}

(Received 22 September 1993; accepted 22 November 1993)

\begin{abstract}
The zeta potential of tristearoylglycerol crystals suspended in olive oil was determined by means of electrophoretic light scattering at high field strengths. The effects of various additives (electrolytes, fatty acids, monoacylglycerols, phospholipids) to the oil phase were investigated. The zeta potentials were generally found to be positive and were strongly influenced by the presence of contaminants or additives. Their values appear to be determined by the presence of native or adsorbed proton acceptor groups on the crystal surface. Phosphatidylcholine proved to be the most effective additive: addition of $0.045 \%(\mathrm{w} / \mathrm{w})$ to the oil raised the zeta potential from about 10 to $60 \mathrm{mV}$.
\end{abstract}

Key words: Electrophoretic light scattering; Olive oil; Tristearoylglycerol; Zeta potentials

\section{Introduction}

During the production of fat spreads, crystals are formed in the oil phase by the cooling of a solution of high melting triacylglycerols ("fat") in low-melting triacylglycerols ("oil"). These subsequently agglomerate into larger aggregates that form a fat crystal network throughout the product. The rate of aggregation of the fat crystals has a considerable influence on the product properties. The agglomeration process does not proceed to the same degree in all cases. This may be due to differences in size and concentration of the elementary fat crystals, but also to differences in the nature and magnitude of the interaction forces between them. Up till now, the van der Waals

\footnotetext{
*Corresponding author.

${ }^{1}$ Present address: Quest International, P.O. Box 2, 1400 CA Bussum, The Netherlands.
}

forces acting between the crystals have been supposed to control their aggregation. However, these forces depend only slightly on the nature of the oil and the fat phase.

In aqueous systems, electrostatic repulsive forces are of paramount importance for controlling aggregation. Their relevance to suspensions in apolar liquids is less commonly accepted but has been established in a number of cases [1]. By providing data of electrophoretic mobilities, the present work is an investigation of whether the aggregation of the fat crystals may be affected by the presence of an electrostatic interaction between them.

\section{Theoretical aspects}

Surface charges on colloidal particles in apolar liquids may be present $[1-3]$ and can be caused by one of the mechanisms which will be discussed here.

The thermodielectric effect $[4,5]$ can be under- 
stood by considering a parallel-plate capacitor which is filled with a material. This material is fluid near one plate and solid near the other plate. Heating or cooling of the first plate causes migration of the boundary surface between the phases parallel to the electrodes and produces a difference in potential between the plates. This effect is thought to be due to a difference in the density of weakly bound electrons in both phases. The extent of charge separation is described by

$Q=K \Delta m$

where $Q$ is the electric charge generated in the thermodielectric cell during the change in mass, $\Delta m$, from phase 2 to phase 1 and $K\left(\mathrm{C} \mathrm{kg}^{-1}\right)$ is the thermodielectric constant, which is regarded as a quantity characteristic of the above process. Values of $K$ are usually of the order of $10^{-7}-10^{-6} \mathrm{C} \mathrm{kg}^{-1}$. (A list of symbols is given in Appendix 1).

Triboelectric charge generation [6-8] can occur in flowing apolar liquids. When such a fluid flows relative to a solid, electrical charges will be generated if ions with a particular charge are adsorbed onto the solid while ions with the opposite charge remain in the fluid. If the conductivity of the fluid is sufficiently low, these charges cannot be dissipated and a net charge builds up in the fluid. During the pumping and agitation of dispersions, relatively large charge separations may arise. Collision of the particles (together with their double layers) against the walls causes a part of the oppositely charged ions to adhere to these walls; this constitutes the origin of the charge separation. Experiments indicate that the conductivity of the liquid is one of the most crucial factors in this phenomenon. If it is less than $10^{-9} \Omega^{-1}$ $\mathrm{m}^{-1}$, charge separations of up to $1500 \mu \mathrm{C} \mathrm{m} \mathrm{m}^{-3}$ may occur [8].

If ionic additives (such as surfactants) are added, the sign of the charge acquired by the particle is determined by the values of the free energy of adsorption of the surfactant cations and anions [3].

If no adsorbable ions are present, the most important mechanism for charge build-up in nonaqueous media is the dissociation of surface groups [3]. In this case, proton transfer is almost entirely responsible for the transfer of the charge between the continuous and the dispersed phase. The dissociation equation is then controlled by the relative basicities and acidities of the solvent and the particle, i.e.

$\mathrm{SH}_{2}^{+}+\mathrm{B}^{-} \leftrightarrow \mathrm{SH}+\mathrm{HB} \leftrightarrow \mathrm{S}^{-}+\mathrm{H}_{2} \mathrm{~B}^{+}$

where HB and SH represent the solvent and a particle respectively.

\section{Principles of measurement}

In the present investigation the zeta potential was measured by electrophoresis. In this method, by applying an external electric field the particles are caused to move relative to the surrounding liquid with a velocity $v$. Henry derived the following equation for a non-conducting particle [9]:

$\frac{v}{E}=\mu=\frac{2 \epsilon_{0} \epsilon_{\mathrm{r}} \zeta}{3 \eta} f(\kappa a)$

where $E$ is the electric field strength, $\mu$ is the electrophoretic mobility, $\epsilon_{0}$ is the permittivity of a vacuum, $\epsilon_{\mathrm{r}}$ is the relative dielectric constant of the fluid, $\zeta$ is the zeta potential, $\eta$ is the viscosity of the medium, $a$ is the particle radius and $f(\kappa a)$ is a function which depends on the shape and size of the particle and the extent of the double layer $1 / k$, where $\kappa$ is given by

$\kappa=\sqrt{\frac{2 z^{2} e^{2} n^{0}}{\epsilon_{0} \epsilon_{\mathrm{r}} k T}}$

Here, $z$ is the valency of ions in the fluid, $e$ is the charge of an electron, $n^{0}$ is the number of ions per unit volume of bulk liquid, $k$ is the Boltzmann constant and $T$ is the absolute temperature.

In non-polar liquids, the thickness of the double layer is generally commensurate or even large relative to the diameter of the particle (Hückcl approximation), so that we expect that $\kappa a<1$. In 
that case, $f(\kappa a) \approx 1$ with a deviation of less than $3 \%$ [9].

The value of $\kappa$ must be known in order to check the validity of this assumption. Because the solubility of electrolytes in oil is very low, $\kappa$ can best be estimated from the conductivity $\Lambda$ of the oil, which is given by

$A=2 n^{0} z e \frac{v_{\mathrm{i}}}{E}$

where $v_{\mathrm{i}}$ is the velocity of the ions and is given by

$v_{\mathrm{i}}=\frac{z e E}{6 \pi \eta r_{\mathrm{i}}}$

where $r_{\mathrm{i}}$ is the ionic radius and $\eta$ is the viscosity of the fluid. Combining Eqs. (3), (4) and (5) leads to

$\kappa=\sqrt{\frac{6 \pi r_{\mathrm{i}} \eta \Lambda}{c_{0} c_{\mathrm{r}} K T}}$

Strictly speaking, the Hückel approximation is valid only for spherical particles. The particles used in the present investigation (fat crystals) are rarely spherical. However, we calculated the zeta potentials, as a first approximation, from the mobility values by dividing it by the constant value $2.3 \times 10^{-10} \mathrm{~m}^{2} \mathrm{~V}^{-2} \mathrm{~s}^{-1}$ the term $(2 / 3) \times\left(\epsilon_{0} \epsilon_{\mathrm{r}} / \eta\right)$ of the Hückel equation). The highest value thus found was $60 \mathrm{mV}$. The highest value of $\kappa a$ obtained from the conductivity experiments was about unity. Up to this value of $\kappa a$, the zeta potential calculated by the Hückel equation for spherical particles closely approximates its exact value [10], so that in this respect no further refinement is necessary. No attempt was made to correct for deviations in particle shape.

Note that owing to relaxation phenomena in the double layer, the function $f$ in principle depends on the valency of the ions in a more complicated way than is suggested here, especially at higher zeta potentials. However, in our case the zeta potentials are usually relatively small, and we assume that the dissociated electrolyte in the apolar oil is only univalent. Under these conditions, with $\kappa a<1$, the effect of the relaxation on $f$ is in most cases completely negligible, but at least much smaller than the uncertainty in our measurements. Therefore we neglect this effect.

\section{Experimental}

\section{Methods}

The electrophoretic mobilities of triacylglycerol crystals in olive oil were measured using a Malvern Zetasizer III equipped with the AZ-26 measuring cell for apolar liquids. This instrument uses heterodyne detection. An IIe-Ne laser beam is split into two beams of equal intensity. At the intersection of the beams an interference pattern consisting of lighter and darker fringes is formed. The movement of the particles through these fringes causes a periodic variation of light scattering, the frequency of which is proportional to the velocity of the particles. By applying a small frequency shift to one of the beams, the interference pattern moves through the observation window. This allows us also to detect the direction of the velocities and any zero velocity of stationary particles.

Very high field strengths are required to determine electrophoretic velocities in the tristearoylglycerol-in-olive-oil system, as may be illustrated by the following example. Let us assume that the zeta potential is $30 \mathrm{mV}$. Because the viscosity of olive oil is approximately $80 \times 10^{-3} \mathrm{~Pa} \mathrm{~s}$ and its relative dielectric constant is approximately 3 , the mobility equals $6.7 \times 10^{-12} \mathrm{~m}^{2} \mathrm{~V}^{-1} \mathrm{~s}^{-1}$. In water, the mobility for the same value of the zeta potential would be $2 \times 10^{-8} \mathrm{~m}^{2} \mathrm{~V}^{-1} \mathrm{~s}^{-1}$.

The high electric field required in non-polar media will, unless the field is perfectly homogeneous, also induce polarization of the particles so that they tend to arrange themselves into chains which then migrate between the electrodes [11].

The dielectric polarizability may also contribute to the electrophoretic velocity. According to Parreira [12], this contribution is proportional to $\nabla E^{2}$ which is a measure of the inhomogeneity of the field (note that the electric field in most electro- 
phoresis cells is actually not homogeneous). The total velocity resulting from the electric field is obtained by adding the dielectric polarization velocity to the electrophoretic velocity as given by for example, the Henry equation (Eq. (2)). The electrophoretic contribution to the total velocity is thus proportional to $E$, while the contribution due to the dielectric polarization is proportional to $\nabla E^{2}$. At low field strengths the electrophoretic contribution predominates, while at higher field strengths the dielectric polarization may play an important rolc. As most clectrophoresis cell electric fields are not homogeneous it is advisable to perform measurements at the lowest possible field strengths.

When plane-parallel plates are employed as electrodes, polarization phenomena can be avoided by performing the measurements in the plane perpendicular to the field at a position midway between the electrodes. In order to satisfy this condition and to maximize the field strength, the AZ-26 cell contains two plane transparent electrodes (surface area, approximately $1 \mathrm{~cm}^{2}$ ), at a distance of $1 \mathrm{~mm}$ apart. By applying a potential difference of about $100 \mathrm{~V}$ between its electrodes, a large field strength is obtained without requiring a dangerously high voltage. Owing to this large electrode area the field can be regarded as homogeneous, so that polarization phenomena may be neglected.

This geometry also produces an interesting secondary effect. In a normal electrophoresis cell, an electro-osmotic gradient (with an accompanying Poiseuille counter-current) is established because the wall carries a charge. The velocity of the particles, therefore, needs to be measured at a level where the electro-osmotic and Poiseuille flows balance each other (the so-called stationary levels). In the present case, however, the vertical distance between the electrodes is so much smaller compared with the distance in the other directions (typically $1 \mathrm{~cm}$ ) that this phenomenon does not play a role. Thus it is possible to perform the measurements anywhere within the cell except near the edges.
Each measurement took $60 \mathrm{~s}$. When the combination of electric field strength and its duration went beyond a critical level, the measured electrophoretic mobilities increased. This is thought to be due to the Wien effect [13]. We will report on this phenomenon in a separate paper. In order to prevent this effect the field $(150 \mathrm{~V}$ over $1 \mathrm{~mm})$ was reversed after $100 / 125 \mathrm{~s}$ (100 "cycles" of $1 / 125 \mathrm{~s}$ each); during reversion the field was set to $0 \mathrm{~V}$ for $1 / 125 \mathrm{~s}$.

\section{Materials and their physical properties}

Tristearoylglycerol (ex BDH Chemicals; melting point $66^{\circ} \mathrm{C}$ ) was recrystallized three times in acetone $(20 \mathrm{~g}$ fat in $300 \mathrm{ml}$ acetone), with approximately $2 \mathrm{~g}$ of Norite (active carbon) added to the solution during the first recrystallization. The melting point of the purified product was $72^{\circ} \mathrm{C}$.

Olive oil (Sigma Diagnostics, catalogue no. $0-1500$ ) was purified by shaking the oil together with silica gel (ratio of oil to silica gel was 10:1) after which the silica gel was removed by filtration using a Millipore filter $(0.15 \mu \mathrm{m})$. After purification, its interfacial tension against distilled water, as determined with a Krüss KT10 tensiometer, was $31.3 \mathrm{mN} \mathrm{m}^{-1}$. Exccedingly pure olive oil has a surface tension of $35 \mathrm{mN} \mathrm{m}^{-1}$ [14]. Owing to auto-oxidation, it is impossible to maintain the purity of the oil for more than a few days. The viscosity $\eta$ of the oil was measured as a function of temperature $t\left({ }^{\circ} \mathrm{C}\right)$ using a Contraves Reomat 115 and can be represented by

$\log \eta=0.52137-1.1907 \log t$

where $\eta$ is in units of Newtons seconds per square metre. The dielectric constant $\epsilon_{\mathrm{r}}$ of the oil was measured using a Boonton Electronics direct capacitance bridge, model $75 \mathrm{C}$, and was found to be 3.1 (literature value; 3.2 [15]).

Two methods were used to measure the d.c. conductivities of the samples.

(i) The dielectric loss angle of the samples was measured over a range of low frequencies. These measurements were performed in a Rhode- 
Schwarz KMF BN 5721 measuring cell using a locally developed loss tangent measuring bridge [16]. The relationship between the loss angle $\delta$ and the d.c. conductivity $\Lambda$ is given [17] by

$\tan \delta=\frac{\epsilon_{\mathrm{r}}^{\prime \prime}}{\epsilon_{\mathrm{r}}^{\prime}}+\frac{A}{\omega \epsilon_{\mathrm{o}} \epsilon_{\mathrm{r}}^{\prime}}$

where $\epsilon_{\mathrm{r}}^{\prime}$ and $\epsilon_{\mathrm{r}}^{\prime \prime}$ are the real and imaginary components of the dielectric constant and $\omega$ is the frequency. The conductivity is then obtained by evaluating the slope of the low frequency part of a plot of $\tan \delta$ versus $\omega$ while assuming that $\epsilon_{\mathrm{r}}^{\prime} \approx \epsilon_{\mathrm{r}}$.

(ii) Liquid conductivities were measured directly using a Keithley Instruments solid state electrometer. In view of the very low values of the conductivities, the agreement between the two methods was satisfactory except for the sample with $0.05 \mathrm{wt} \%$ Epikuron.

The following additives were used: Epikuron 145, Epikuron 170 and Epikuron 200 (Lucas Meyer; the compositions of these phospholipids are given in Appendix 2), monostearoylglycerol p.a. (Fluka), oleic acid p.a. (Merck), stearic acid (Merck) and silica gel 60 reinst (Merck).

\section{Sample preparation}

The preparation of the fat suspensions has to be rigidly standardized in order to allow mutual comparison between samples. We used the following procedure. The desired amount of tristearoylglycerol was added to a known quantity of olive oil and was dissolved by heating the mixture for approximately $15 \mathrm{~min}$ at $72^{\circ} \mathrm{C}$. The hot solution was then transferred to a test tube $(16 \mathrm{~mm}$ in diameter, filled to a height of $9 \mathrm{~cm}$ ), cooled during $10 \mathrm{~min}$ in a water-filled constant-temperature bath maintained at $2^{\circ} \mathrm{C}$ by means of a cryostat, and was held at this temperature for $25 \mathrm{~min}$. This period proved to be sufficient to produce samples which showed good scattering and consisted of particles that were not too large. After $25 \mathrm{~min}$ the test tube was removed from the bath and stored at room temperature $\left(22^{\circ} \mathrm{C}\right)$. After about $1.5 \mathrm{~h}$ the sample was transferred to a syringe and injected into the Zetasizer; the measurements were performed again at $22^{\circ} \mathrm{C}$. The measured values of the zeta potential proved to be independent of the time after injection. Thus certain samples were measured repeatedly over a period of several days without any change in the zeta potential. During these operations, precautions were taken to reduce moisture as far as possible. The influence of the moisture content on the zeta potential was also investigated directly by comparing two samples, one of which had been dried with well-desiccated silica gel, while the second sample was watersaturated by shaking with an equal volume of water, after which the phases were separated by centrifugation. In both cases the zeta potential was found to have the same value.

The additives were added to the purified olive oil before the tristearoylglycerol was added. $\mathrm{NaCl}$, $\mathrm{HCl}$ and $\mathrm{NaOH}$ were added to the oil by shaking their aqueous solutions together with the oil phase. Monostearoylglycerol, oleic acid and the phospholipids were dissolved in the heated oil phase. Consequently, crystallization took place in the presence of these additives and may have been influenced by their presence.

The size of the fat crystals was measured under the microscope. The samples consisted of a free dispersion of plate- and needle-like particles, with a maximum particle size of about $2 \mu \mathrm{m}$.

\section{Results}

The measured conductivities of the samples are presented in Table 1 . The values of $\kappa$ were calculated by means of Eq. (6) from the average values of the measured conductivities, assuming a ionic radius $r_{\mathrm{i}} \approx 0.1 \mathrm{~nm}$ and a particle radius $a=10^{-6} \mathrm{~m}$. The results support the use of the Hückel equation for the interpretation of the measurements, especially if we take into account that ions may be considerably larger than the supposed value of $10^{-10} \mathrm{~m}$.

The values of the zeta potentials represent the results of a large number of measurements on a 
Table 1

Conductivity of olive oil with and without additives

\begin{tabular}{|c|c|c|c|}
\hline Sample & $\begin{array}{l}\text { Measuring bridge } \\
\text { conductivity } \\
\left(\Omega^{-1} \mathrm{~m}^{-1}\right)\end{array}$ & $\begin{array}{l}\text { Keithley } \\
\text { conductivity } \\
\left(\Omega^{-1} \mathrm{~m}^{-1}\right)\end{array}$ & $\kappa a^{\mathrm{a}}$ \\
\hline Purified olive oil & $1.8 \times 10^{-12}$ & $2.3 \times 10^{\cdots 12}$ & 0.16 \\
\hline Impure olive oil & $5.5 \times 10^{12}$ & $4.4 \times 10^{12}$ & 0.26 \\
\hline $\begin{array}{l}\text { Purified olive oil, } 0.2 \% \text { purified fat, } \\
0.05 \% \text { stearic acid }\end{array}$ & $9.9 \times 10^{-11}$ & $5.3 \times 10^{-11}$ & 1.1 \\
\hline Purified olive oil, 0.05 stearic acid & $4.8 \times 10^{-12}$ & $4.4 \times 10^{-12}$ & 0.25 \\
\hline Purified olive oil, 0.05 Epikuron 200 & $3.4 \times 10^{-11}$ & $1.3 \times 10^{-10}$ & 1.1 \\
\hline
\end{tabular}

${ }^{\text {a Assuming }} a=10^{-6} \mathrm{~m}$ and $r_{\mathrm{i}}=10^{-10} \mathrm{~m}$.

variety of samples. The tabulated spread indicates that the measurements have a relative error of $10-15 \%$. At low values of the zeta potential (a few millivolts) this error may even become $50 \%$.

Table 2 presents the zeta potentials measured on samples in the absence of intentional additives. Only the purity of the fat and the oil then excrt any influence. The data relate to the purity of the oil and the tristearoylglycerol (where $i$ and $p$ denote impure and pure respectively), the quantity of tristearoylglycerol added, the measured values of the zeta potential and the standard deviation of its average value.

We also introduced $\mathrm{HCl}, \mathrm{NaOH}(\mathrm{pH}$ between 1.8 and 11) or $\mathrm{NaCl}$ by shaking a purified oil phase together with the electrolyte containing the

Table 2

Zeta potentials in the absence of additives

\begin{tabular}{|c|c|c|c|c|}
\hline \multirow{2}{*}{$\begin{array}{l}\text { Fat } \\
\text { (wt.\%) }\end{array}$} & \multicolumn{2}{|c|}{ Purity } & \multicolumn{2}{|c|}{ Zeta potential } \\
\hline & Oil & Fat & $\begin{array}{l}\text { Value } \\
(\mathrm{mV})\end{array}$ & $\begin{array}{l}\text { Standard } \\
\text { deviation } \\
(\mathrm{mV})\end{array}$ \\
\hline 0.1330 & $\mathrm{i}$ & $\mathrm{i}$ & 15.4 & 3.0 \\
\hline 0.225 & $\mathrm{i}$ & i & 17.8 & 2.1 \\
\hline 0.241 & $\mathrm{i}$ & $\mathrm{i}$ & 15.2 & 2.4 \\
\hline 0.207 & $\mathrm{i}^{\mathrm{a}}$ & $\mathrm{i}$ & 16.0 & 1.4 \\
\hline 0.231 & $\mathrm{i}$ & $\mathrm{p}$ & 4.1 & 0.9 \\
\hline 0.270 & $\mathrm{p}$ & $\mathrm{i}$ & 7.9 & 1.0 \\
\hline 0.253 & $\mathrm{p}$ & $\mathrm{p}$ & 2.1 & 1.3 \\
\hline
\end{tabular}

Key: i, not purified; p, purified.

ail filtered. water phase before adding 0.2 mass $\%$ fat to the oil phase. Only with $1 \mathrm{M} \mathrm{NaCl}$ in the aqueous phase were significant effects on the zeta potential visible; the zeta potential changed from 8 to $-3 \mathrm{mV}$ (in the case of non-purified fat) or from 2 to $-2 \mathrm{mV}$ (in the case of purified fat).

With mixtures of purified oil and purified fat $(0.1-0.2 \%)$ the effects of a few additives that chemically resemble oil and fat were investigated. Adding oleic acid (at $0.3 \%$ ), monostearoylglycerol (at $0.1 \%$ ) or stearic acid (at $0.014 \%$ ) increased the zeta potential of the fat crystals by a few millivolts (from 2 $\mathrm{mV}$ to $8 \mathrm{mV}, 6 \mathrm{mV}$ and $10 \mathrm{mV}$ respectively).

More extensive measurements were conducted for stearic acid because its effect on the zeta potential is much larger than that of any other component discussed until now. For these measurements, again both purified fat and purified oil were

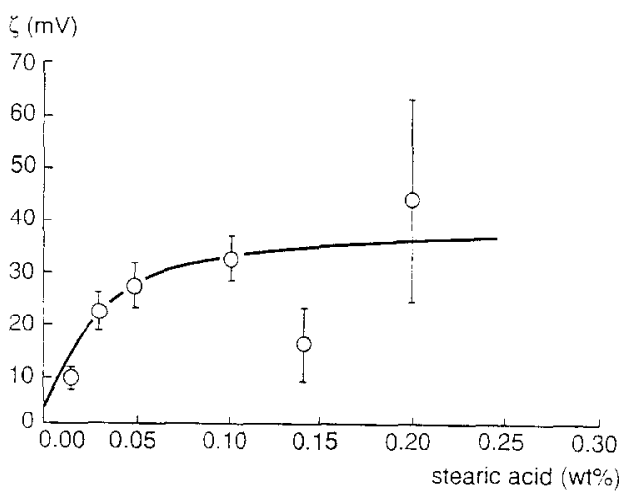

Fig. 1. Effect of stearic acid on the zeta potential of fat crystals in olive oil: $0.2 \%(\mathrm{w} / \mathrm{w})$ fat in suspension. 
used. Figure 1 gives a graphical representation of the effect of stearic acid on the zeta potential for $0.2 \%(\mathrm{w} / \mathrm{w})$ fat dispersions. Above concentrations of approximately $0.1 \mathrm{wt} . \%$ stearic acid, the spread in the measured values increases rapidly.

The effect of the addition of three types of Fpikuron is even larger than that of monostearoylglycerol, as is shown in Table 3. The largest effect is produced by Epikuron 200. The concentration of Epikuron is only known within an accuracy of 0.003 wt.\% because it is a very sticky substance, so that quantitative manipulation of small samples is difficult.

\section{Discussion}

\section{Mechanism producing the surface charge}

The results clearly demonstrate that fat crystals in oil carry a charge. The size of this charge strongly depends on the purity of the fat and the oil as well as on the type of additive. Earlier, four mechanisms were described that might produce the electric charge on the particles. Of these, the thermodielectric and the triboelectric effects will be shown to be negligible.

It follows from Eq. (1) that the surface charge density $\sigma_{0}$ generated by the thermodielectric effect on a particle with an equivalent spherical radius $a$ that crystallizes from the oil is given by $\sigma_{0}=\rho a K / 3$

Table 3

Zeta potentials with Epikuron as additive

\begin{tabular}{lllll}
\hline $\begin{array}{l}\text { Fat } \\
\text { (wt.\%) }\end{array}$ & $\begin{array}{l}\text { Type of } \\
\text { Epikuron }\end{array}$ & $\begin{array}{l}\text { Concentration } \\
\text { (wt.\%) }\end{array}$ & $\begin{array}{l}\text { Zeta } \\
\text { potential } \\
(\mathrm{mV})\end{array}$ & $\begin{array}{l}\text { Standard } \\
\text { deviation } \\
(\mathrm{mV})\end{array}$ \\
\hline 0.201 & 145 & 0.009 & 9.4 & 1.0 \\
0.198 & 145 & 0.031 & 20.4 & 1.0 \\
0.194 & 170 & 0.010 & 16.5 & 1.5 \\
0.207 & 170 & 0.033 & 38.5 & 4.0 \\
0.201 & 200 & 0.004 & 26.4 & 4.0 \\
0.198 & 200 & 0.011 & 27.9 & 2.5 \\
0.197 & 200 & 0.030 & 49.5 & 4.9 \\
0.196 & 200 & 0.047 & 62.0 & 6.0 \\
\hline
\end{tabular}

Both fat and oil had been purified. where $\rho$ is the fat crystal density. The corresponding zeta potential, assuming spherical geometry, can be estimated from this surface charge density [9] by

$\zeta=\frac{\sigma_{0}}{\epsilon_{0} \epsilon_{\mathrm{r}} \kappa}=\frac{\rho a K}{3 \epsilon_{0} \epsilon_{\mathrm{r}} \kappa}$

Using $K=10^{-6} \mathrm{C} \mathrm{kg}^{-1}$ and $\kappa=7 \times 10^{5} \mathrm{~m}^{-1}$ in an apolar liquid leads to an overestimation of $\zeta=0.08$ $\mathrm{mV}$ for $1 \mu \mathrm{m}$ particles. Thus the thermodielectric effect is negligible in our case.

The magnitude of triboelectric charge acquisition can likewise be expressed in terms of the zcta potential. The charge separation per volume $\left(Q_{v}\right)$ is related to the surface charge density by $\sigma_{0}=$ $Q_{\mathrm{v}} a / 3$. Using Eq. (10) and an (overestimated) value of $1500 \mu \mathrm{C} \mathrm{m}^{-3}$ for $Q_{\mathrm{v}}$, a zeta potential of $0.09 \mathrm{mV}$ is found. The conclusion is that the triboelectric potential is negligibly small as well. Thus the surface charge must be caused either by the selective adsorption of ions or by the dissociation of surface groups.

The zeta potential of fat crystals in olive oil: the influence of additives

The zeta potential of fat crystals in olive oil is almost always positive and is strongly influenced by the presence of impurities and additives. The zeta potential decreases with increasing purity of the fat and oil phases and may be close to zero in the absence of impurities. Impurities that are readily adsorbed on the fat crystal surface have the greatest effect. Thus the influence of stearic acid on the zeta potential is much larger than that of oleic acid. This difference might be related to their chemical structure: the straight hydrocarbon chains of stearic acid can be incorporated in tristearoylglycerol more readily than the kinked chains of oleic acid. Direct adsorption measurements could be carried out to confirm these indirect results relating to adsorption.

Depending on the conditions, fatty acids can act either as proton donors or as proton acceptors. 
Our experiments indicate that, in the present system, fatty acid molecules constitute stronger proton acceptors than the triacylglycerols on which they adsorb: thus the slightly adsorbing oleic acid increases the zeta potential only slightly, whereas the strongly adsorbing stearic acid strongly increases this potential. Thus<smiles>[R]C(=O)C([R])(O)O</smiles>

will proceed more readily than<smiles>[R]OC([R])([R])[O]</smiles>

We suggest that the factor that limits the charge transfer to the fat crystals is the number of protonacceptor groups on their surface rather than the number of molecules of fatty acid present in the oil. This does not, however, explain why protons tend to adsorb. However, our measurements suggest the presence of this mechanism.

At stearic acid concentrations above 0.1 wt. $\%$, the scatter in the readings increased markedly. At this concentration, the stearic acid may form either separate crystals or mixed crystals with tristearoylglycerol. The former assumption was tested by preparing a solution of 0.3 wt.\% stearic acid in olive oil, which was subsequently kept at $2^{\circ} \mathrm{C}$ for $90 \mathrm{~min}$. No precipitate was formed. Thus the effect of stearic acid appears to be due to the formation of mixed crystals.

The presence of salt from aqueous $1 \mathrm{M} \mathrm{NaCl}$ caused a slight decrease in the zeta potential. This suggests that negative ions were adsorbed somewhat more readily by the fat than were positive ions. Inorganic hydroxides or acids up to a level of about $10^{-2} \mathrm{M}$ in the water phase had no noticeable effect; higher concentrations of these electro-

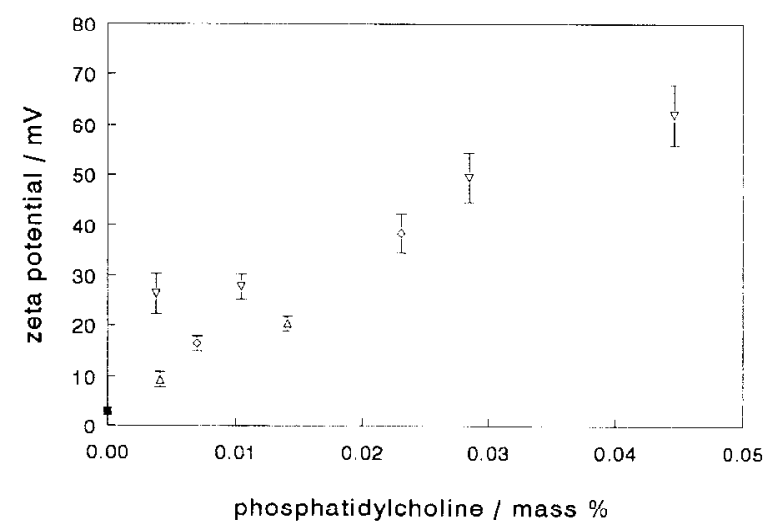

Fig. 2. Zeta potential of fat crystals in olive oil vs. the concentration of Epikuron $200(+), 170(0)$ and $145(\mathbf{E})$ at a level of $0.2 \%(w / w)$ fat in suspension.

lytes were not useful, as chemical reactions were expected.

The addition of phospholipids, which have been reported to adsorb strongly on fat crystals dispersed in oil [18], also produced positive zeta potentials. Again, their presence on the crystal surface appears to increase strongly the number of proton-acceptor groups, resulting in enhanced proton transfer.

The component responsible for the increase in zeta potential proved to be phosphatidylcholine. Analysis of the phospholipids used (see Appendix 2) shows the content of phosphatidylcholine in Epikuron 145, Epikuron 170 and Epikuron 200 to be $45 \%, 70 \%$ and more than $95 \%$ respectively. When the zeta potentials presented in Table 3 are plotted against the phosphatidylcholine content of each system, the results for the various types of Epikuron nearly coincide (Fig. 2).

\section{Conclusion}

The zeta potential of fat crystals in olive oil can be measured, although only by using a method capable of registering extremely low velocities (approximately $10^{-7} \mathrm{~m} \mathrm{~s}^{-1}$ ). When the signal was processed by means of the autocorrelation of the light intensity, laser-Doppler anemometry proved to be a suitable method, provided that high field 
strengths $\left(1.5 \times 10^{5} \mathrm{~V} \mathrm{~m}^{-1}\right)$ were used. The applied field strengths were, however, not so high that phenomena which interfere with clectrophoresis occurred. An important condition for the application of this method is that the sample produces good scattering of the light.

Since the solid phase is formed by crystallization in the continuous phase, the sample preparation procedure must be accurately controlled. The following process parameters are important: the temperature of crystallization $\left(2^{\circ} \mathrm{C}\right)$, the crystallization period ( $25 \mathrm{~min}$ ) and the tristearoylglycerol concentration (approximately 0.2 wt.\%).

The zeta potential was found to be positive in almost all cases and was strongly influenced by the presence of contaminants (and/) or additives. Neither the thermodielectric effect nor triboelectric charge acquisition produced a significant contribution to the zeta potential. The zeta potential decreased with increasing purity of the fat and oil phases. Addition of $\mathrm{NaOH}, \mathrm{HCl}$ and $\mathrm{NaCl}$ from an aqueous solution had little influence on the zeta potential. Monostearoylglycerol and oleic acid produced a somewhat larger effect, but still resulted in relatively low values. Stearic acid showed a more noticeable effect. The zeta potential was, however, influenced most strongly by Epikuron, of which phosphatidylcholine proved to be the active ingredient. A concentration of approximately $0.01 \%$ of this component already resulted in a zeta potential of $27 \mathrm{mV}$, while a concentration of $0.045 \%$ even produced a zeta potential of more than $60 \mathrm{mV}$.

\section{References}

1 Ph.C. van der Hoeven, Ph.D. Thesis, Agricultural University, Wageningen, 1991.

2 R.M. Fuoss, Chem. Rev., 17 (1935) 27.

3 E.J.W. Verweij, Recl. Trav. Chim. Pays Bas, 60 (1941) 625

4 P. Eyerer, Adv. Colloid Interface Sci., 3 (1972) 223.

5 A. Dias Tavares, Phys. Lett., 93 (1983) 145.

6 A. Klinkenberg, J.L. van der Minne, Electrostatics in the Petroleum Industry, Elsevier, Amsterdam, 1958.

7 A. Schuringa and C. Luttik, J. Sci. Instrum., 37 (1960) 332.

8 H. Krämer, J. Electrostat., 10 (1981) 89.

9 R.J. Hunter, Zeta Potential in Colloid Science, Academic Press, London, 1981, p. 71.
10 R.W. O'Bricn and L.R. White, Trans. Faraday Soc., 2, 74 (1987) 1607

11 L. Marshall and C.F. Zukoski, J. Chem. Soc., Faraday Trans. 1, 85 (1989) 2785.

12 H.C. Parreira, J. Chem. Phys., 49 (1968) 4711.

13 M. Wien, Ann. Phys., 5 (1929) 400.

14 F. Groeneweg, personal communication, 1992.

15 G.L. Bell and F.Y. Poynton, Philos. Mag., 49 (1925) 1065.

16 Th. Kwaaitaal, IEEE Trans. Instrum. Meas., 39 (1990) 874.

17 A.R. von Hippel, Dielectrics and Waves, 1st edn. MIT Press, Cambridge, MA, 1966, p. 4.

18 D. Johansson and B. Bergenståhl, poster P2 presented at the 10th Scandinavian Symp. on Surface Chemistry, Turku, 1989.

\section{Appendix 1: List of symbols}

a particle radius $(\mathrm{m})$

$e \quad$ elementary charge $\left(1.6 \times 10^{-19} \mathrm{C}\right)$

$E \quad$ electric field strength $\left(\mathrm{V} \mathrm{m}^{-1}\right)$

$k$ Boltzmann constant $\left(1.38 \times 10^{-23} \mathrm{~J} \mathrm{~K}^{-1}\right)$

$K \quad$ thermodielectric constant $\left(\mathrm{C} \mathrm{kg}^{-1}\right)$

$m \quad$ mass $(\mathrm{kg})$

$n_{\mathrm{i}}^{0} \quad$ number of ions of type i per unit volume in the bulk solution $\left(\mathrm{m}^{-3}\right)$

$Q \quad$ electric charge (C)

$Q_{\mathrm{v}} \quad$ charge separation per volume $\left(\mathrm{C} \mathrm{m}^{-3}\right)$

$r_{\mathrm{i}} \quad$ ionic radius

$t$ temperature $\left({ }^{\circ} \mathrm{C}\right)$

$T \quad$ absolute temperature $(\mathrm{K})$

$v \quad$ velocity $\left(\mathrm{m} \mathrm{s}^{-1}\right)$

$v_{\mathrm{i}} \quad$ velocity of ions $\left(\mathrm{m} \mathrm{s}^{-1}\right)$

$Z_{i} \quad$ velocity of ion $\mathrm{i}$

\section{Greek letters}

$\delta \quad$ loss angle

$\epsilon_{0} \quad$ permittivity of a vacuum $\left(8.9 \times 10^{-12}\right.$ $\mathrm{Fm}^{-1}$ )

$\epsilon_{\mathrm{r}} \quad$ relative permittivity (equal to the dielectric constant)

$\epsilon^{\prime} \quad$ real component of dielectric constant

$\epsilon^{\prime \prime} \quad$ imaginary component of dielectric constant

$\zeta \quad$ zeta potential (V)

$\eta \quad$ viscosity of the medium ( $\mathrm{Pa} \mathrm{s}$ )

$\kappa \quad$ reciprocal Debye length $\left(\mathrm{m}^{-1}\right)$

$A \quad$ d.c. conductivity $\left(\Omega^{-1} \mathrm{~m}^{-1}\right)$ 


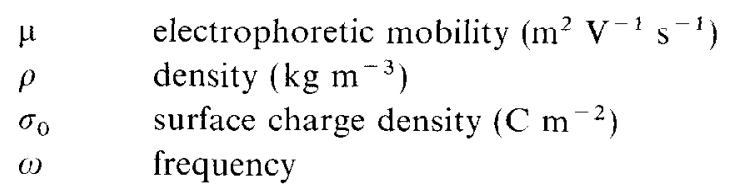

\section{Appendix 2: Analytical data for Epikuron}

\section{Epikuron 145}

\section{Composition:}

Phosphatidylcholine

Phosphatidylethanolamine

Phosphatidylinositide

Lysophosphatidylcholine

Phosphatidic acid

Other phospholipids

Glycolipids

Water, remaining oil content

Analytical results:

Phosphorus

Iodine number

Peroxide number

\section{Epikuron 170}

\section{Composition:}

Phosphatidylcholine

$11-15 \%$

Max. $3 \%$
$90-95$

Max. 5

$68-72 \%$
Phosphatidylethanolamine

Lysophosphatidylcholine

Other phospholipids

$10-13 \%$

Max. $4 \%$

$10-12 \%$

and glycolipid

Water, remaining oil content Max. 3\%

Analytical results:

Phosphorus

$3.5-3.7 \%$

Iodine number

92-97

Peroxide number

Max. 5

Epikuron 200

Composition:

Phosphatidylcholine

Min. 95\%

Lysophosphatidylcholine

Max. $4 \%$

Water, remaining oil content Max. 3\%

Analytical results:

Phosphorus

$3.6-3.9 \%$

Iodine number

94-99

Peroxide number 